\title{
Promoting sustainable development in the minerals industry: the phosphate project in Saudi Arabia
}

\author{
M. Aldagheiri \\ Department of Geography, Qassim University, Saudi Arabia
}

\begin{abstract}
The Kingdom of Saudi Arabia is largely considered to be a single-commodity economy in that the oil sector is the most important pillar of the national economy while the non-oil sectors play a relatively weak role. National economic diversification is considered a strategic goal for the Saudi Arabian government. The minerals sector in Saudi Arabia is one of the economic activities which has already started to achieve this strategic goal of diversification away from oil-related activities as the main source of national income. Saudi Arabia has strategic industrial minerals such as phosphate, bauxite, high-grade silica and gypsum as well as industrial raw materials that can be used in the domestic, regional and overseas markets. The industrial minerals sector in Saudi Arabia recognises sustainable development as a vital objective for society and readily acknowledges its responsibility for helping to achieve this critical aim. This paper examines the phosphate project which is considering one of the industrial minerals important to the economy of the Kingdom of Saudi Arabia, focusing on its production, the structure of its industry and the effects of government policies and planning efforts.
\end{abstract}

Keywords: industrial minerals, phosphate, sustainable development, Saudi Arabia.

\section{Introduction}

National economic diversification is considered a strategic goal for the Saudi Arabian government particularly when the exportable natural resources are expected to deplete in the foreseeable future. The minerals sector in Saudi Arabia is one of the economic activities that has already started to achieve this strategic 
goal of diversification away from oil-related activities as the main source of national income. Although non-oil mineral activities are far less significant than oil activities, their development has the potential to contribute to the economic diversification of the Saudi economy. Exploration and development of nonhydrocarbon mineral resources has, therefore, been a consistent objective of the government throughout successive Development Plans.

The territory of the Kingdom contains abundant strategic minerals such as phosphate and bauxite, as well as industrial raw materials that can be used in the domestic, regional and overseas markets after processing. The diversified geological terrain, strong economy and strategic location of Saudi Arabia in the GCC countries are among the most fundamental features attracting investment in the mineral industry. Furthermore, it is hoped that this sector will become a major source of revenue generation for the Kingdom during the next decade. New mines and associated investments will also create employment opportunities in the Kingdom.

\section{The importance of study}

The Kingdom of Saudi Arabia is largely considered to be a single-commodity economy, in that the oil sector is the most important pillar of the national economy, while the non-oil sectors play a relatively weak role. National economic diversification is considered a strategic goal for the Saudi Arabian government. The minerals sector in Saudi Arabia is one of the economic activities which has already started to achieve this strategic goal of diversification away from oil-related activities as the main source of national income. Saudi Arabia has strategic industrial minerals such as phosphate, bauxite, high-grade silica and gypsum as well as industrial raw materials that can be used in the domestic, regional and overseas markets. The industrial minerals sector in Saudi Arabia recognises sustainable development as a vital objective for society and readily acknowledges its responsibility for helping to achieve this critical aim. This paper examines the Al Jalamid phosphates project which is considering one of the industrial minerals important to the economy of the Kingdom of Saudi Arabia, focusing on its production, the structure of its industry and the effects of government policies and planning efforts.

\section{The phosphates in Saudi Arabia}

Saudi Arabia is home to some of the largest phosphate deposits in the world. These deposits are located mostly in the north and north-western regions in a belt stretching across the entire northern section of the Kingdom (see map 1). The phosphate rock is hosted in a sedimentary sequence of Paleocene to Eocene age that extends to the north into Iraq and Syria and west into Jordan. The phosphate reserves are part of a shelf sequence of rocks that marks the edge of the Tethys Sea, an ocean in past geological time that is now occupied by the Mediterranean and the countries surrounding its shores. It is the largest and most extensive phosphate province in the world [1]. 


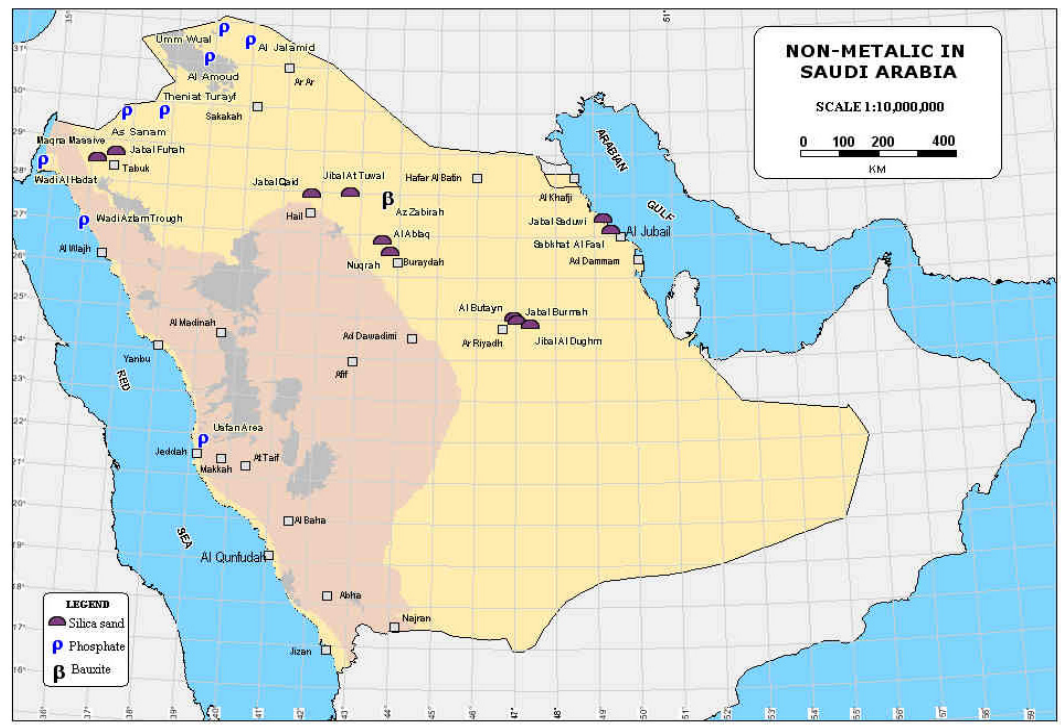

Map 1: $\quad$ Non-metallic minerals in Saudi Arabia.

According to Ma'aden's President, Dabbagh [2], the Kingdom's phosphate is estimated at 3.1 billion tons, of which 1.6 billion tons is an estimated reserve, with 1.5 billion tons as a mineable resource. In addition to the Al-Jalamid Mine Project, there is an estimated 313 million tons of phosphate ore reserve extending for an area of $18 \mathrm{~km} 2$. Spencer [3] stated that with private sector investment, Saudi Arabia can exploit the produced phosphate locally to consolidate its position as third ranked exporter of fertilizers in the world. Also, DMMR anticipates that the country will capture 16 per cent of the world phosphate market. Identified future markets for phosphate include China, India, Japan, Pakistan, and Iran.

Phosphate accumulations in Saudi Arabia are known in four regions: SirhanTurayf, the coastal Red Sea, and the central and eastern Regions. Deposits with economic potential have been established in the Sirhan-Turayf region that extends into Jordan, southern Iraq and Syria but in the others further work is not justified. Sedimentary phosphorite was first identified in Saudi Arabia in 1965 in the Turayf area during drilling for water wells by ARAMCO close to the Tapline, about 70 kilometers to the east of Turayf city. In the same year, reconnaissance mapping led to another discovery of a phosphate bed in the Thaniyat-Turayf area, 250 kilometers southwest of Turayf. In 1988, the Sannam deposit was discovered by the US Geological Survey (USGS) and Deputy Ministry For Mineral Resources (DMMR). Furthermore, continued exploration works indicate prospects for other resources in Widyan Ar-Rushaydah, Amud and Al-Fihah areas [4]. 
Al Jalamid phosphates are considered to be the best explored and largest deposit in the Kingdom, and are located about 120 kilometers east-southeast of Turayf city. Since the discovery of the deposit in 1984, DMMR's work has advanced from the exploration phase to a feasibility study which was completed in late 1992. The Al-Jalamid deposit is estimated to contain 313 million tons of mineable resource. Ma'aden expects the Al-Jalamid deposit to have an annual yield of 11 million tons/year for 27 years, including 4.5 million tons of phosphate concentrates [5].

Al Jalamid phosphate is the largest single project for the Ma'aden planners and is centered on a world-class deposit of phosphates. This resource could become a significant new source of exportable fertilizer in the form of dominium phosphate (DAP), which contains double the nutrient value of unprocessed rock. This is a big project which would require the establishment of infrastructure for mining, processing and transport. Ma'aden estimates that the deposits within its exploration programmes will lead to the establishment of a phosphate industry and a number of downstream industries in the Kingdom. Ma'aden views the phosphate resources of Al-Jalamid as a nucleus around which a number of industrial projects can be established.

Another resource prospect for phosphate mining in the Kingdom is the Umm Wu'al area, situated around 70 kilometers west of the Al-Jalamid deposit. This deposit was under extensive exploration indicating promising techno-economical potential with estimated reserves of about 208 million tons of phosphate deposits. Ma'aden, through international qualified consultants, has conducted the ore reserve evaluation and ore beneficiation and processing tests on both lab and pilot scales with objectives to assess the proven reserves, confirm the ore amenability to beneficiation and chemical processing and optimize its industrial flow sheets. The findings of these studies will be included in a feasibility study and utilized to identify local or foreign joint venture partners to develop this site.

Relying on the Saudi Geological Survey (SGS), the Sanam phosphate beds correlate with the Thaniyat member of the Jalamid Formation and consist of two units. The area has not yet been explored in detail, but a resource study in 1999 showed a demonstrated resource of $23 \mathrm{Mt}$ averaging 16.91 per cent. A particular attraction of Sanam is its relative proximity to the Red Sea, 250 kilometers, in contrast to the 1,000 kilometers distance from Al Jalamid to the Arabian Gulf. Thaniyat phosphate occurs at several levels in the Thaniyat Member at the base of the Jalamid Formation. Part of the Thaniyat area was explored under licence by Granges International Mining in 1977-81. Al Amud phosphate beds of the Arqah Phosphorite Member in the Al Amud area are largely covered by basalt and have been explored by only 27 drill holes. In the Quraymiz Area there are two thin and low-grade phosphorite bed outcrops in an escarpment for about 20 kilometers in the Quraymiz area. Six drill holes show no development of phosphorite beds to the north. Moreover, there are several areas in the Kingdom such as the Red Sea region (Maqna massif, Azlam trough and Usfan Area), Central region and Eastern region. 


\section{Al Jalamid phosphates project}

This project lies in the northern part of the Kingdom, about 120 kilometres eastsoutheast of Turayf city. The feasibility study for this project was prepared by the Ma'aden-Saudi Oger consortium and S.N.C. Lavalin of Canada and Jacobs of the U.S., and this study includes according to Abdullah S. Busfar, vicepresident for corporate projects [6] "The project consists of a phosphate mine and a beneficiation plant at Al-Jalamid, in Northern Saudi Arabia, a fertilizer production complex at Ras Az Zawr, on the shore of the Arabian Gulf."

The feasibility study indicates that the Al Jalamid phosphate is estimated to contain 313 million tons of phosphates able to provide sustained production for at least 27 years. Also, the feasibility study indicates that 11 million tons of $\mathrm{Al}$ Jalamid phosphate will be mined annually, upgrading the concentration of ore to 32 per cent to produce 4.5 million tons of phosphate concentrates. This project is considering the largest single project that is occupying the thinking of Ma'aden planners is centered on a world-class deposit of phosphates. This resource could become a significant new source of exportable fertilizer in the form of dominium phosphate (DAP), which contains double the nutrient value of unprocessed rock. This is a big project and its location in the northern undeveloped part of the country would require the establishment of infrastructure for mining, processing and transport [7].

Ma'aden assessed the mining plan at the Al Jalamid project to optimize equipment utilization. The deposits will be exploited by drilling and blasting, while draglines will remove the overburden and front-end loaders. Ma'aden also will provide the Al Jalamid project with a basic infrastructure, in that the energy for the project will be made available via turbine generators fired by fuel oil, with an installed capacity of 28 megawatt. Three water wells drilled and tested at the Al Jalamid site prove a sufficient water resource exists for the life of the project and hydrological modelling of the underlying Tawil aquifer has revealed a sustainable flow rate of 13 million cubic metres per year [8]. The initial plan for this project is to mine and beneficiate phosphate rock. The phosphate rock will then be transported via the North-South Railway (NSR) to the industrial city of Ras Az Zawr for conversion into dominium phosphate (DAP) fertilizer for export. The DAP export is expected to be phased into the market by 2013 to reach about 3 million tons per year.

The Ras Az Zawr site is about 60 kilometres north of Jubail Industrial City on the Arabian Gulf. Ras Az Zawr is a huge new industrial centre designed to serve the Kingdom's emerging minerals sector and has an $\$ 8$ billion investment which will comprise the industries of the phosphate and aluminum projects. The main elements of the industrial centre at Ras Az Zawr will be three 4.1 million tons per year sulphuric acid plants, three 1.4 million tons per year phosphoric acid plants, and one 650,000 tons per year ammonia plant, to produce about 2.9 million tons per year dominium phosphate. The basic infrastructure of the industrial centre will include accommodation and utility services, port facilities, a 1,800 megawatt power plant, sub-stations and switchgear plus a dedicated port for Panamax-sized ships of up to 60,000 tons. In a press conference after the 
inauguration, Ali Al-Naimi, Minister of Petroleum and Mineral Resources and Chairman of Ma'aden Board of Directors, asserted that "Ma'aden will build one of the first Mining Cities in the Middle East that will accommodate in one site all basic facilities for the production of mineral industries from mine to final product. He noted that the city will contribute in a unique manner to the growth of Saudi Arabia's Mining Industry" [9].

The estimated cost of the phosphate projects at Ras Az Zawr is around \$1.9 billion, plus additionally about $\$ 400$ million to develop the mines at the $\mathrm{Al}$ Jalamid site. In an interview the President of Ma'aden Dr. Al-Dabbagh said that the availability of molten sulphur and natural gas from within the Kingdom as a feedstock alongside the local phosphate rock will make it a highly competitive integrated production facility within easy reach of growing Asian markets. Ma'aden intends to use the phosphate rock in the production of a number of value added products, such as fertilizers, chemicals, animal feed, and detergents. After the dominium phosphate plant reaches peak production in five years time, Saudi Arabia will be in direct competition with producer countries such as Morocco, Jordan and the USA, as it will produce a quarter of the world's DAP production. Furthermore, Al-Naimi [10] said in that the phosphate fertilizer project will boost the Kingdom's non-oil exports and make the Kingdom the third largest producer of phosphate fertilizer in the world.

In general, the development of the Al Jalamid phosphate project relies on the following comparative advantages:

- availability of abundant low-cost energy in the form of petroleum and natural gas products;

- availability of ammonia at competitive prices in Jubail;

- availability of abundant sulphur in Jubail;

- geographic proximity of the Jubail complex to the Asian markets;

- market opportunities following the decline of production in Florida which has decreased by one third during the past decade; and

- approval of the necessary transport link between the Al Jalamid phosphates deposits and Ras Az Zawr.

Based on Ma'aden the development initiation of Al-Jalamid integrated phosphate project will be beneficial due to the following:

1. Maintain the Kingdom's future export capability through diversification of its products where the huge phosphate resources will play a major element;

2. Provide employment opportunities to Saudi work force, which is expected to directly employ about 6,000 personnel;

3. Indirect benefits to Saudi work force and institutions through related industrial and social services about 40,000 personnel;

4. Enhancing urban development in the Northern Region;

5. Provide a transfer of technology in the field of phosphate fertilizers and other related chemical industries; and

6. Enhancing foreign capital investment. 


\section{Conclusion}

Regarding the significance of the minerals industry, the case study has shown that the mining sector has great potential to play a leading role in the Sustainable development and the diversification of the Saudi economy due to the Kingdom's enormous and relatively untapped mineral occurrences, large area (more than 2,000,000 square kilometres) and the increasing demand for raw materials both in domestic as well as international markets. The minerals industry in Saudi Arabia, which includes phosphate, will become one of the main activities attracting foreign investment, and during the next decade it is hoped will be one of the causes of considerable economic growth in the region and the country. The minerals sector will become a third pillar of the economy after hydrocarbons and petrochemicals. The mineral industry will also have several positive effects on the national economy, such as constituting a source of additional revenue for the government, increasing exports and contributing to export diversification, creating new opportunities for the creation of industrial activities in the Kingdom.

Al Jalamid phosphates will play a major role in the Kingdom's future exports. This project will enhance urban development in the Northern Region of the Kingdom. The phosphate industry provides a transfer of technology in the field of phosphate fertilizers and other related chemical industries. According to Ma'aden's estimates the phosphate fertilizer, with encouraging economic indicators, would make the Kingdom the world's third largest producer of phosphate fertilizer. According to Ma'aden the minerals industry will create employment opportunities which will generate 6,000 direct jobs and 40,000 indirect jobs for Saudi citizens who will work in the building and operating of the industry and associated projects.

\section{References}

[1] Ma'aden, Exploration, Mining and Processing, Ma'aden Magazine, Riyadh, Saudi Arabia, 2004.

[2] Dabbagh, A, Saudi Arabia to Offer Gold Mining Licenses to Foreign Firms, Ma'aden News Letter, Riyadh, Saudi Arabia, 2004.

[3] Spencer, H., Industrial Minerals of Saudi Arabia and their Uses in New Material, Internal Report, Jeddah: DMMR, 1999.

[4] DMMR, The developing of Mineral Exploration in The Kingdom, Ministry of Petroleum and Mineral Resources, Jeddah, Saudi Arabia (in Arabic), 1999.

[5] USABC, The Mining Sector in The Kingdom of Saudi Arabia, Report, U.S. - Saudi Arabian Business Council, 2005.

[6] Busfar, A., Maaden to Build the Largest Phosphate Plant in 2005, Arab News, March 01, 2005.

[7] Ma'aden, Exploration, Mining and Processing, Ma'aden Magazine, Riyadh, Saudi Arabia, 2004. 
58 Sustainable Development and Planning V

[8] Ma'aden, Phosphate: Fertilizer for the future, Ma'aden News Letter, Issue 3, Riyadh, Saudi Arabia, 2003.

[9] Ma'aden, Al-Naimi Inaugurates Mining City Civil Works, Ma'aden News Letter, Issue 4, Riyadh, Saudi Arabia, 2005.

[10] Al-Naimi, A., \$4.1b Phosphate Ventures Open to Foreign Investors, the Saudi Gazette - March 28, 2004. 